\title{
FORTIFICATION OF YOGURTS WITH VITAMIN D AND CALCIUM ENHANCES THE INHIBITION OF SERUM PARATHYROID HORMONE AND BONE RESORPTION MARKERS: A DOUBLE BLIND RANDOMIZED CONTROLLED TRIAL IN WOMEN OVER 60 LIVING IN A COMMUNITY DWELLING HOME
}

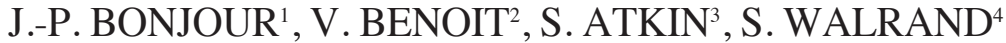

\begin{abstract}
1. Division of Bone Diseases, University Hospitals and Faculty of Medicine, Geneva, Switzerland; 2. Groupe de Recherche Nutritionnelle, Yoplait, 150 rue Gallieni, 92641 Boulogne, France; 3. Diabetes and endocrinology research Centre, 220 - 236 Anlaby Road, Hull, HU3 2RW England; 4. UMR 1019, Centre de Recherche de Clermont-Theix-Lyon, Clermont Ferrand, France. Corresponding author: Jean-Philippe Bonjour, M.D. Division of Bone Diseases, Geneva University Hospitals and Faculty of Medicine, Rue Gabrielle Perret-Gentil 4 , CH - 1211 Geneva 14, Switzerland, Phone:+4122 37299 60, Fax:+4122 372 99 73, E-mail: jean-philippe.bonjour@unige.ch
\end{abstract}

\begin{abstract}
Objective: To evaluate whether fortification of yogurts with vitamin D and calcium exerts an additional lowering effect on serum parathyroid hormone (PTH) and bone resorption markers (BRM) as compared to iso-caloric and iso-protein dairy products in aged white women at risk of fragility fractures. Design: A randomized double-blind controlled trial. Setting: A community dwelling home. Participants: Forty-eight women over 60 years (mean age 73.4). Intervention: Consumption during 84 days of two $125 \mathrm{~g}$ servings of either vitamin D and calcium-fortified yogurts (FY) at supplemental levels of $10 \mu \mathrm{g}$ vitamin D3/d and $520 \mathrm{mg} / \mathrm{d}$ of calcium (total $=800 \mathrm{mg} / \mathrm{d}$ ), or non fortified control yogurts (CY) providing $280 \mathrm{mg} / \mathrm{d}$ of calcium. Measurements: Serum changes from baseline (D0) to D28, D56 and D84 in 25OHD, PTH and in two BRM: Tartrate-resistantacid-phosphatase-isoform-5b (TRAP5b) and carboxy-terminal-cross-linked-telopeptide of type-I-collagen (CTX). Results: The 10 years risk of major and hip fractures were 13.1 and $5.0 \%$, and 12.9 and $4.2 \%$, in FY and CY groups, respectively. From D0 to D84, serum 25OHD increased (mean \pm SE) from $34.3 \pm 2.4$ to $56.3 \pm 2.4 \mathrm{nmol} / \mathrm{L}$ in FY $(n=24)$ and from $35.0 \pm 2.5$ to $41.3 \pm 3.0 \mathrm{nmol} / \mathrm{L}$ in $\mathrm{CY}(\mathrm{n}=24),(\mathrm{P}=0.00001)$. The corresponding changes in PTH were from $64.1 \pm 5.1$ to $47.4 \pm 3.8 \mathrm{ng} / \mathrm{L}$ in $\mathrm{FY}$ and from $63.5 \pm 4.6$ to $60.7 \pm 4.2 \mathrm{ng} / \mathrm{L}$ in $\mathrm{CY}(\mathrm{P}=0.0011)$. After D84, TRAP5b was reduced significantly $(\mathrm{P}=0.0228)$ and $\mathrm{CTX}$ fell though not significantly $(\mathrm{P}=0.0773)$ in FY compared to CY. Conclusion: This trial in aged white women living in a community dwelling home at risk for osteoporotic fractures confirms that fortification of dairy products with vitamin D3 and calcium should provide a greater prevention of secondary hyperparathyroidism and accelerated bone resorption as compared to nonfortified equivalent foods.
\end{abstract}

Key words: Osteoporosis prevention, nutritional intervention, calcium-vitamin D fortified yogurts, secondary hyperparathyroidism, bone resorption.

\begin{abstract}
Abbreviations: FY: vitamin D and calcium-fortified yogurt; CY: control (non fortified) yogurt; Ca: calcium; Pi: inorganic phosphate; 25OHD: 25-hydroxyvitamin D; PTH: parathyroid hormone; BRM: bone resorption marker; CTX: carboxy-terminal-cross-linked-telopeptide of type-I-collagen; TRAP5b: tartrate-resistant-acid-phosphataseisoform-5b; IGF-I: Insulin-like growth factor-I; BMD: bone mineral density; BTM: bone turnover markers; DXA: dual X-ray energy aborptiometry.
\end{abstract}

\section{Introduction}

Vitamin D, through its active metabolite 1,25-dihydroxyvitamin $\mathrm{D}(1,25(\mathrm{OH}) 2 \mathrm{D})$, plays an essential role for translocating dietary $\mathrm{Ca}$ across the intestinal epithelium, thereby raising the extracellular $\mathrm{Ca}-\mathrm{Pi}$ product to the level required for the adequate mineralization of the bone organic matrix. This physiological link explains why adequate supplies of both vitamin $\mathrm{D}$ and $\mathrm{Ca}$ are required to support bone health throughout life (1). When their supply is insufficient, homeostatic mechanisms operate to prevent hypocalcaemia by both stimulating the production and secretion of parathyroid hormone (PTH) which, in turn, enhances both the renal conservation and the bone resorption of $\mathrm{Ca}$. Thus, inadequacy in the vitamin D supply, as expressed by a decreased serum 25-hydroxyvitamin D (25OHD), leads to secondary hyperparathyroidism (1), and elevated serum markers of bone resorption (2). The serum biochemical pattern encompassing low 25OHD, high PTH, elevated CTX and TRAP5b characterizes the insufficient supply of vitamin D associated with low $\mathrm{Ca}$ intake, as often observed with aging (3). Increasing the supply of both vitamin $\mathrm{D}$ and $\mathrm{Ca}$ tends to correct these biochemical anomalies within a few weeks or months (3). The long-term impact of such correction is an attenuation of bone loss, a reduced risk of falling and fragility fractures (4-7).

Intervention with pharmacological agents documented that early measurements in serum bone resorption markers predict the rate of bone loss (8) and the incidence of fragility fractures (9). As recently reviewed (10), the predictive value of early change in bone biochemical markers is of particular interest for clinical research in nutrition. Indeed, studies comparing the effects of different foods on bone structural component outcomes, let alone on fragility fractures, are difficult or even 
impossible to conduct in randomized placebo-controlled trials of long duration (11).

Short-term evaluation is particularly appropriate for assessing the selective effects of food fortification on both skeleton trophic factors and biochemical bone turnover markers (BTMs). Such an assessment implies the comparison of the response to foods that only differ by the addition or not of the tested nutrient(s). This clinical investigation approach can be considered as lying within the conceptual scope of "Comparative Effectiveness Research (CER)" (12). So far, few studies have applied a CER design in the field of clinical nutrition, such as that comparing the effects of two plant-source forms of calcium supplements on bone mineral density (13).

In conformity with the CER concept, we recently published a randomized controlled trial in which consumption of vitamin $\mathrm{D}$ and $\mathrm{Ca}$ fortified yogurts, as compared to non fortified equivalent dairy products, exerted a greater positive impact on bone trophic factors and BTMs after 8 weeks (3). This randomized controlled trial was carried out in institutionalized elderly women (mean age: 86 years) with quite a low baseline vitamin $\mathrm{D}$ status, as documented by a serum level of $25 \mathrm{OHD}$ of $18 \mathrm{nmol} / \mathrm{L}$ (3). This concentration is well below the level of $50 \mathrm{nmol} / \mathrm{L}$, considered by the Institute of Medicine (IOM) as meeting the requirements of $97.5 \%$ of the North-American population (14), let alone the much higher level of $75 \mathrm{nmol} / \mathrm{L}$ estimated as adequate in the Endocrine Society Clinical Practice Guideline (15).

Therefore, it remained to be documented that the same fortified dairy product could also favourably affect skeletal trophic factors and BTMs in women with a vitamin D insufficiency other than the deficiency documented in elderly women living in French nursing homes (3). This hypothesis was tested in a 12 week randomized controlled trial enrolling women over 60 (mean age: 74 years) living in a community home in England. As compared to the previous study (3), the new cohort displayed a baseline 25(OH)D serum level about twice $(\sim 34 \mathrm{nmol} / \mathrm{L})$ as high than that recorded in older French institutionalized women. Despite these substantial differences in age, environmental living conditions and baseline vitamin D status, the results presented here confirm the gain in efficacy of the tested dairy product on bone related factors.

\section{Subjects and methods}

\section{Subjects}

A total of 96 women living in a sheltered accommodation housing in Hull (England) were screened for eligibility. The recruitment for eligibility started after the Research and Development review board of the Hull \& East Yorkshire Hospital NHS Trust approved the protocol on April 23, 2012: "Permission for Research R1307". One single investigator conducted the study, in accordance to the Helsinki Declaration, the Good Clinical Practices (GCPs) and in compliance with English national regulations. Of this initial group, 28 subjects did not fulfill the serum 25OHD and PTH inclusion criteria; 10 subjects withdrew consent and 1 died. Thus, 57 women responded to the inclusion criteria: aged $>60$ years, with a prior medical check-up suitable for research purposes, serum levels of $25 \mathrm{OHD} \leq 20 \mathrm{ng} / \mathrm{mL}$ and PTH $<150 \mathrm{ng} / \mathrm{mL}$. They were enrolled between May 29, 2012 and July 18, 2012, all having given their informed consent. The age ranged from 61 to 90 years, with mean $( \pm \mathrm{SD})$ age $73.4 \pm 7.5$ years (median: 73.4 years).

\section{Exclusion criteria}

Exclusion criteria included concomitant diseases or any illness affecting Ca-Pi metabolism such as primary hyperparathyroidism; osteoporotic fracture during the year preceding the study; chronic gastrointestinal disease, chronic renal failure, hepatic and cardiac failure or cancer. Treatment during the last 6 months for osteoporosis or other bone diseases, including pharmaceutical agents such as: bisphosphonates, raloxifen, teriparatide, strontium ranelate and denosumab. Glucocorticoid therapy. Lactose intolerance. Participation in a clinical trial during the 3 months preceding the entry into the study. Confinement to bed.

\section{Design and conducted trial.}

It was a monocentric randomized double-blind comparative study conducted in two parallel groups, in which subjects were allocated to consume daily 2 yogurts of $125 \mathrm{~g}$ each, providing either $10 \mu \mathrm{g}$ (400 IU) of vitamin D3 and $800 \mathrm{mg}$ of elemental $\mathrm{Ca}($ Fortified Yogurt $=\mathrm{FY})$ or $0 \mu \mathrm{g}$ of supplemental vitamin D3 and $280 \mathrm{mg}$ of elemental $\mathrm{Ca}($ Control Yogurt $=\mathrm{CY})$ during 84 days. Before the fortification process, both FY and CY contained $140 \mathrm{mg}$ of milk Ca per serving. To fortify one type of yogurt (FY) vitamin D3 was added in powder form and $\mathrm{Ca}(+260 \mathrm{mg} /$ serving $)$ as citrate salt. Both vitamin D3 and Ca citrate were mixed with fruit (strawberry, cherry or apricot) preparation used as flavoring components to the two types (FY and CY) of yogurts. Yoplait France provided the yogurts.

A random number table was used with blocks of four to determine the allocation sequence. The random allocation was centralized, computer-generated, and stratified by the investigating center. The two types of yogurts were presented in identical packs. In order to insure the blinding, they were designated with two code letters (A and B) and the code only broken after the statistical analysis had been fully completed. The two servings of $125 \mathrm{~g}$ of either type of yogurts daily provided similar amounts of proteins (FY: $7.8 \mathrm{~g}$; CY: $8.0 \mathrm{~g}$ ), energy (FY: $232 \mathrm{kcal}$; CY: $248 \mathrm{kcal}$ ), lipids (FY: $6.2 \mathrm{~g}$; CY: $6.5 \mathrm{~g}$ ) and carbohydrates (FY: $33 \mathrm{~g}$; CY: $36 \mathrm{~g}$ ). They were recommended to be consumed one at lunchtime, the other at dinner.

From the 57 enrolled subjects (CY: 29; FY: 28), 6 (3 in each group) left the study without any follow-up evaluation carried out. From the 51 participants (CY: 26; FY: 25), 3 had to be excluded because of some major deviation from 


\section{JNHA: GERIATRIC SCIENCE}

the protocol due to the introduction of either osteoporosis treatment or vitamin D supplementation (CY: 2; FY: 1). Thus, in 48 subjects (24 in each group), serum analysis of 25OHD, PTH, CTX and TRAP5b were measured at all time points (D0, D28, D56 and D84) enabling the assessment of the changes in these 4 biochemical variables from the onset to the end of the intervention.

\section{Compliance and Satisfaction Evaluation}

A compliance and satisfaction form on the yogurt consumption was completed daily by each of the participants, and monthly by the dieticians and nurses of the sheltered accommodation center. The questionnaire included a question concerning how much yogurt was consumed and reason for any incomplete intake. At D28, D56 and D84, four questions on the satisfaction of consuming either type of yogurts were asked in relation to: flavor; pot size adapted to appetite; limitations of intake at both lunch and dinner; lack of interest in maintaining intake.

\section{Clinical assessment}

Fracture risk evaluation. The 10 year risk of hip and major osteoporotic fracture of each participant was computed by using the probability model FRAX ${ }^{\circledR}$ (16) calibrated to the United Kingdom population. The prediction of fracture with the use of clinical risk factors alone in FRAX, i.e. without a DXA test, is comparable to the BMD measurement alone (17).

Dietary survey at baseline and during the intervention. Ca, proteins and energy intakes were assessed at baseline (D0) and at the end of the intervention (D84). Food consumption was recorded by 3-day dietary diaries (18).

Sun exposure. The participants were asked to report if, at any time, they spent more than 20 minutes daily with uncovered arms exposed to the sun.

\section{Biochemical analysis}

The blood samples were collected in the morning after an overnight fast and stored at -70 o $\mathrm{C}$ until analysis. Serum $\mathrm{Ca}$ and inorganic phosphate $(\mathrm{Pi})$ were measured by colorimetry (Roche Diagnostics, Rotkreuz, Switzerland). Serum 25OHD, PTH, CTX and TRAP5b, were measured by enzyme-linked immunosorbent assay (ELISA) on the Bio-Rad Microtech Microplate Reader. The following immunoassay kits were used: 25OHD, CTX and TRAP5b (Immunodiagnostics System, Fountain Hills, AZ, USA); PTH (Human Bioactive PTH Elisa kit, Immunotopics, San Clemente, CA, USA). The intraassay and inter-assay variations including the variations for TRAP5b were less than 6.0 and 8.0\%, respectively. Analytical measurements were made in duplicates for PTH, CTX and TRAP5b.

\section{Statistical analysis}

The main aim of the trial was to demonstrate that consumption of fortified as compared to non-fortified yogurts exerted more favorable effects on vitamin D status (increased serum 25OHD), secondary hyperparathyroidism (decreased serum PTH) and decreased BRMs (serum CTX and TRAP5b). Determination of the sample size was estimated from the effects on changes in serum TRAP5b. It was expected that a difference of $10 \%$ in serum TRAP5b changes would be detected between the two groups with a power of $80 \%$ and two-sided alpha of 0.05. Such a $10 \%$ difference in change in TRAP5b required a sample of 15 participants per group, taking into account a standard deviation of inter-individual difference of $9.3 \%$ (19). 29 and 28 subjects in CY and FY groups, respectively, were eventually enrolled into the study and randomized. The data are expressed as mean \pm SE. Differences between quantitative data measured at D0 and changes from D0 to D84 were evaluated by the MannWhitney U test or Student $t$ test to determine whether or not the individual values were normally distributed. The differences in time courses (from D0 to D84), type of yogurts and interactions between time course and type of yogurts for serum $25(\mathrm{OH}) \mathrm{D}$, PTH, CTX and TRAP5b were evaluated by repeated-measure analysis of variance (ANOVA) with adjustment by the Tukey's test. Statistical analysis of the data was conducted by using SAS V9.2 (SAS Institut Inc, Cary, NC, USA) and STATA software version 9.2 (StataCorp LP, College Station TX, USA). In addition, chi-square tests were used (20) to compare the proportion of $\mathrm{FY}$ vs $\mathrm{CY}$, with serum values of $25(\mathrm{OH}) \mathrm{D} \geq 50$ $\mathrm{nmol} / \mathrm{L}$ (the IOM sufficiency threshold (14)), and of PTH $\leq 46$ $\mathrm{ng} / \mathrm{L}$ (the normal range limit) after 84 days of intervention. The $P$ value $<0.05$ was considered statistically significant.

\section{Results}

\section{Characteristics at baseline (Day 0)}

The demographic characteristics at the inclusion into the trial (D0) did not differ between the CY and FY randomized groups (Table 1). At baseline, using the FRAX questionnaire specifically adapted to the UK population, it appeared that the estimated 10-year risk of major osteoporotic fractures, or hip fracture alone, was not different between the CY and FY group (Table 1). The similarity FRAX scores fracture could be expected given that both quantitative and qualitative risk factors did not differ between the two groups. The dietary intakes of $\mathrm{Ca}$, energy, proteins, carbohydrates and lipids, as recorded in 20 and 16 participants in the $\mathrm{CY}$ and FY group, respectively, did not differ significantly (Table 2). At baseline (D0), there was no significant difference in serum 25OHD, PTH, CTX and TRAP5b between the two groups (Table 3).

\section{Response to fortified foods}

The time-dependent change in serum 25OHD was more pronounced in the FY than in the CY groups (Figure 1). After 84 days it was about 4 times larger $(\mathrm{P}=0.00001)$ in $\mathrm{FY}$ than $\mathrm{CY}$ (Table 3). The rise serum $25(\mathrm{OH}) \mathrm{D}$ greater in FY than in $\mathrm{CY}$ at $\mathrm{D} 84$ was associated with a significantly $(\mathrm{P}=0.0011)$ greater decrease in serum PTH (Figure 2). The differences in 
percent changes between 25(OH)D and PTH from D0 to D84 are illustrated in Figure 3. At D84, the proportion of subjects with a serum level $\geq 50 \mathrm{nmol} / \mathrm{L}$ was $70.8 \%$ (17/24) and $16.7 \%$ $(4 / 24)$ in the FY and CY groups, respectively (chi square test $\mathrm{P}<0.001)$. After the same intervention time, the proportion of subjects with a serum PTH level $\leq 46 \mathrm{ng} / \mathrm{L}$ was $58.3 \%(14 / 24)$ and $25 \%(6 / 24)$ in the FY and CY groups, respectively (chi square test $\mathrm{P}<0.05)$.

Table 1

Participants' Characteristics at Baseline : Demography and Fracture risk

\begin{tabular}{lcc}
\hline & $\begin{array}{c}\text { CY Group } \\
\text { (N= 24) }\end{array}$ & $\begin{array}{c}\text { FY Group } \\
(\mathbf{N = 2 4 )}\end{array}$ \\
\hline Age (year) & $72.8(1.6)$ & $74.3(1.4)$ \\
Standing Height $(\mathrm{cm})$ & $160.0(1.4)$ & $161.8(1.2)$ \\
Body Weight $(\mathrm{kg})$ & $79.8(3.2)$ & $76.1(2.7)$ \\
BMI (kg/m2) & $31.1(1.1)$ & $29.2(1.1)$ \\
10 Year Risk of Major Fractures (\%) 1) & $12.9(1.2)$ & $13.1(0.9)$ \\
10 Year Risk of Hip Fracture (\%) 1) & $4.2(0.8)$ & $5.0(0.9)$ \\
\hline
\end{tabular}

Values of control (CY) and fortified (FY) yogurt groups are means (SE); 1) Calculated from the WHO-FRAX rating scale, adapted to the UK population. No difference between $\mathrm{CY}$ and and FY group was statistically significant.; BMI: Body mass index.

\section{Figure 1}

Serum level of 25(OH)D in subjects consuming either nonfortified (CY) or vitamin D and Ca-fortified (FY) yogurts

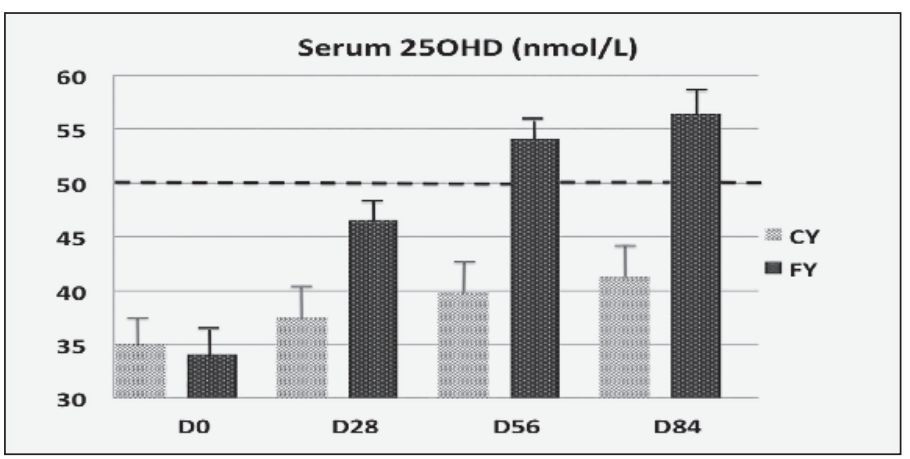

25OHD was determined in serum samples collected at baseline (D0), and 4 (D28), 8 (D56) and 12 (D84) weeks after the beginning of the intervention in subjects consuming either non-fortified control yogurts (CY) or fortified yogurts (FY) (means in $\mathrm{nmol} / \mathrm{L}+/-\mathrm{SE}$ ). The dashed line corresponds to the serum 25OHD level considered as sufficient in the 2011 IOM report (14). Number of subjects: 24 in each group. $\mathrm{P}=0.00001$ by repeated-measures ANOVA for the difference between the two types of yogurts.

The more pronounced fall in serum PTH in the FY group, compared to $\mathrm{CY}$ group, was associated with a significant reduction in serum TRAP5b (Figure 3). There was also a reduction in serum CTX, the other marker of bone resorption, though the difference between FY and CY did not reach the level of statistical significance (Figure 3). There was a significant interaction between the time course and the type of yogurt for serum 25OHD (Table 3), but not for serum PTH that also tended to fall in the CY group (Figure 2).
Table 2

Participants' Dietary Intakes at Baseline

\begin{tabular}{lcc}
\hline & CY Group $(\mathbf{N}=\mathbf{2 0})$ & FY Group $(\mathbf{N}=16)$ \\
\hline Ca $(\mathrm{mg} / \mathrm{d})$ & $710(45)$ & $782(75)$ \\
Energy $(\mathrm{kcal} / \mathrm{d})$ & $1377(48)$ & $1379(86)$ \\
Proteins $(\mathrm{g} / \mathrm{d})$ & $60(3)$ & $61(5)$ \\
Carbohydrates $(\mathrm{g} / \mathrm{d})$ & $146(8)$ & $152(12)$ \\
Lipids $(\mathrm{g} / \mathrm{d})$ & $59(3)$ & $55(4)$ \\
\hline
\end{tabular}

Values of control (CY) and fortified (FY) yogurt groups are means (SE); They were calculated by 3 -day dietary diaries and were available in subgroups of randomized participants. No difference between CY and and FY group was statistically significant.

\section{Other monitored variables}

The Ca intake recorded by 3-day dietary diaries was $710 \pm 45$ at D0 and $869 \pm 44 \mathrm{mg} / \mathrm{d}$ at D84 in the CY group. It was $783 \pm 75$ at D0 and $1457 \pm 57 \mathrm{mg} / \mathrm{d}$ at D84 in the FY group. The calcium relative increase was $33 \%$ and $115 \%$ in the $\mathrm{CY}$ and $\mathrm{FY}$ group, respectively. Meanwhile, in both $\mathrm{CY}$ and FY groups, the consumption of energy and protein did not significantly differ between D0 and D84 (data not shown).

\section{Figure 2}

Serum level of PTH in subjects consuming either non-fortified yogurts(CY) or vitamin D and Ca-fortified (FY) yogurts

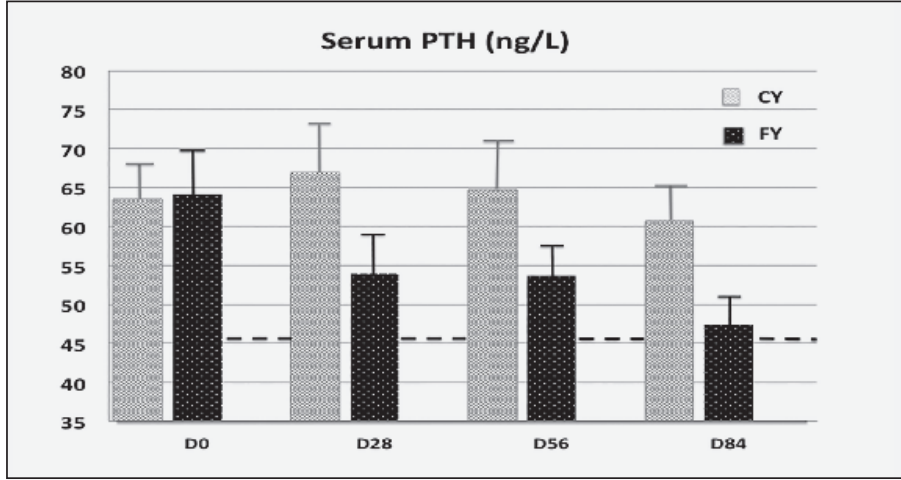

PTH was determined in serum samples collected at baseline (D0), and 4 (D28), 8 (D56) and 12 (D84) weeks after the beginning of the intervention in subjects consuming either non-fortified control yogurts (CY) or fortified yogurts (FY) (means in ng/L+/- SE). The dashed line corresponds to the upper level of the normal range of PTH. Number of subjects: 24 in each group. $\mathrm{P}=0.0075$ by repeated-measures ANOVA for the difference between the two types of yogurts.

The serum $\mathrm{Ca}$, Pi, prealbumin, and albumin did not significantly change between D0 and D84 in either group. Likewise for body weight, systolic and diastolic blood pressure (data not shown).

Sun exposure. During the intervention, none of the subjects spent daily more than 20 minutes outdoors with their uncovered arms exposed to the sun. 
Table 3

Participants' Serum Biochemistry at Baseline (D0), 28 (D28), 56 (D56) and 84 (D84) Days of Control (CY) or Fortified (FY) Yogurt Comsumption a

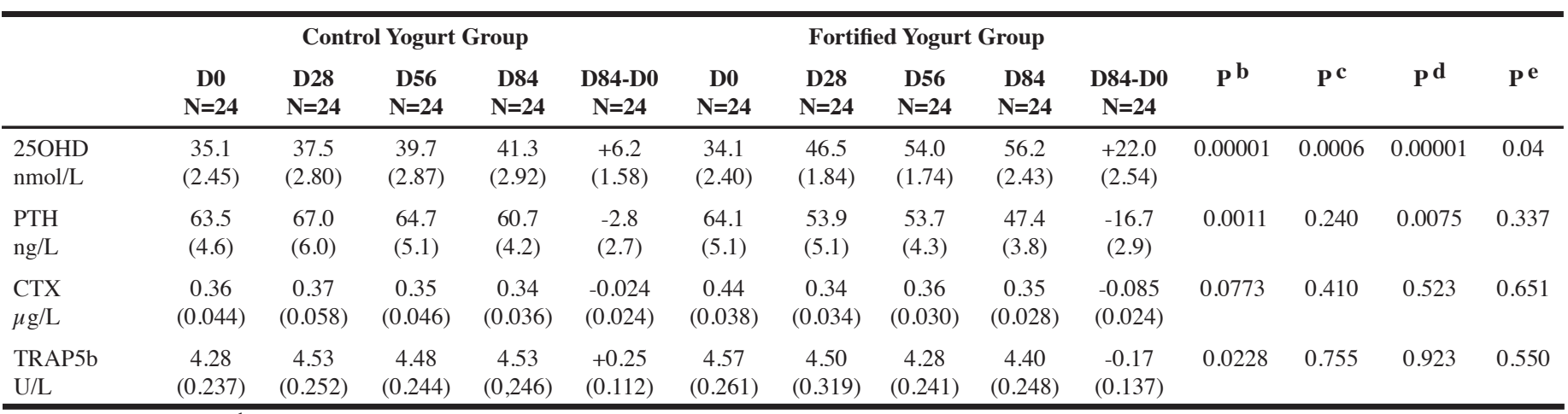

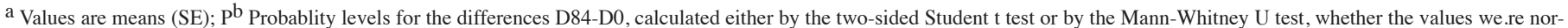

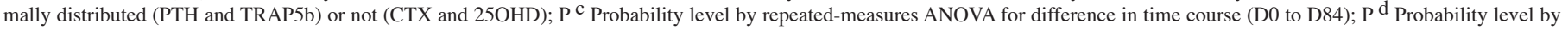

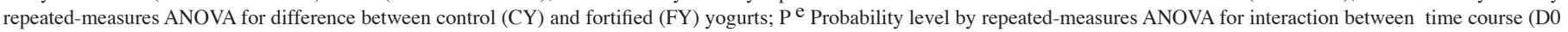
to D84) and type (CY vs. FY) of yogurts.

\section{Figure 3}

Percent change in serum 25OHD, PTH, CTX and TRAP5b after 84 days of consumption of control yogurts (CY) as compared to vitamin D and calcium-fortified yogurts (FY)

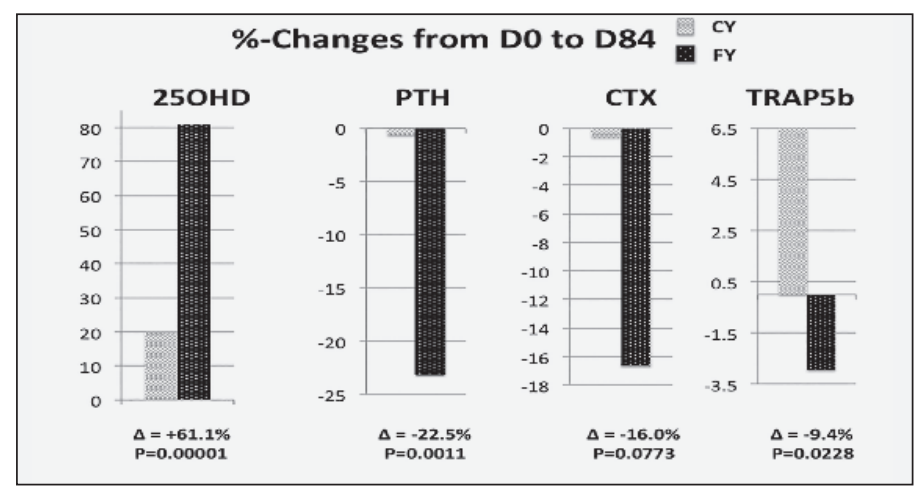

Values are means in percent after 84 days (D84-D0/D0 x 100) of intervention in subjects consuming non-fortified control (CY) and fortified yogurts (FY), respectively. $\Delta=$ Difference in percent between CY and FY groups; Number of subjects: 24 in each group; P. Probability levels for the differences D84-D0, calculated either by the two-sided Student $t$ test or by the Mann-Whitney U test, whether the values were normally distributed (PTH and TRAP5b) or not (CTX and 25OH).

\section{Acceptability and adherence}

The two types of yogurts were well tolerated. The acceptability in terms of flavor and portion size was considered as appropriate. The mean compliance throughout the intervention was more than $95 \%$ in both groups, despite the fact that consuming two yogurts per day is rather unusual in an English diet.

\section{Discussion}

The serum biochemical pattern encompassing low vitamin D status, secondary hyperparathyroidism and increased bone resorption indices characterizes the insufficient supply of vitamin $\mathrm{D}$ associated with inadequate Ca intake. This pattern tends to be more frequently observed with aging. The related biochemical anomalies can be corrected within a few weeks or months by providing an adequate supply of both vitamin D and $\mathrm{Ca}$. Such correction is associated with an attenuation of bone loss, a reduced risk of falling and osteoporotic fractures (4-7). These beneficial effects of vitamin D supplementation in conditions of deficiency or insufficiency can be observed with much lower-dose regimens than those that can be detrimental to bone health (21). Indeed, vitamin D supply can be inefficient in community-dwelling individuals with vitamin D sufficiency (22). Controversy on the outcome of vitamin D on bone health, fragility fractures and falls can be explained, at least in part, by differences between: supplemental doses; duration of supplementation; ethnic/racial target populations; baseline vitamin D status (21-30). Furthermore, interpretation in terms of inadequacy/adequacy of serum 25OHD baseline levels and-or intervention-induced changes in response to supplemental vitamin D can differ when related to the concept of the "Estimated Average Requirement (EAR) or to the "Recommended Dietary Allowance (RDA)", as well as to the method of assessment $(31,32)$. The notion of inadequacy/ adequacy of the vitamin D status is still much more difficult to delineate when putative extraskeletal effects are considered. Indeed, from association findings mostly, it has been suggested that vitamin D insufficiency could be implicated as a causal or at least as a contributing factor to several chronic diseases including type 2 diabetis, cardiovascular disease, some cancers, autoimmune and infectious disorders $(15,33)$. Cognitive functions have also been positively associated with the vitamin D status (34-37). This link could be implicated in the risk of falling that might be, at least in part, explained by some deficit in both attention and executive functions. The direct causal relationship between vitamin $\mathrm{D}$ and the various chronic diseases mentioned above remains to be established in 


\section{DAIRY FORTIFICATION ON SERUM 25OHD, PTH AND BRM}

appropriately designed prospective studies.

The foregoing randomized controlled trial was essentially focused on the effects of two nutrients on bone-related metabolism. It confirms the results of a previous similar study (3) showing that fortification of the same dairy product with vitamin $\mathrm{D} 3$ and $\mathrm{Ca}$, as compared to the identical non fortified food, enhances vitamin D status, corrects secondary hyperparathyroidism and, concomitantly, reduces biochemical markers of bone resorption. This confirmation, with results supported by intention-to-treat analysis, as in the previous study (3), is of interest since these two trials differed on several important demographic and environmental aspects.

The former trial was carried out in institutionalized women with mean age 86 (3). These participants were entirely dependent on long-term care facilities. The nursing staff provided a comprehensive assistance during the trial, including the regular delivery of meals to the participants. In contrast, in the current study, the participants were younger, with mean age 74 . They were free living in sheltered accommodation where tenants are able to look after themselves with a degree of independence. This setting implied that their eating habits could be maintained. Although the new reported outcomes are qualitatively quite similar to those of the previous study (3), there are some quantitative differences between the two trials that deserve to be commented in relation with the distinct demographic and environmental conditions. The better vitamin D status in the current study, as compared to the other "twin" study (3), could be putatively explained by factors such as age (74 vs. 86 years) and-or living conditions (community dwelling vs. nursing home) that may have influenced the supply of vitamin D from both cutaneous and food sources (38).

The changes in the serum 25OHD in response to $10 \mu \mathrm{g}$ supplemental vitamin D3, as compared to the non fortified yogurts, were at D56 less important in the present study (FY: $+19.9 ; \mathrm{CY}:+4.6 \mathrm{nmol} / \mathrm{L}$, difference $=+15.3 \mathrm{nmol} / \mathrm{L}$ ) than in the previous report (3), (FY: +25.3 ; CY: +5.2 : difference $=$ $+20.1 \mathrm{nmol} / \mathrm{L}$ ). This $24 \%$ reduced response could be accounted for by the known inverse relationship between the baseline serum level of $25(\mathrm{OH}) \mathrm{D}$ and its increment following an oral intake of supplemental vitamin D3 $(39,40)$. Indeed, at D0, the level of serum 25OHD in the FY group was about $80 \%$ higher in the present report (FY Group : $34.1 \pm 2.4 \mathrm{nmol} / \mathrm{L}$ ) than in the previous comparable intervention study (FY Group: $19.2 \pm 1.2 \mathrm{nmol} / \mathrm{L}$ ) testing the same dairy product (3). In the present trial, after 56 days of FY consumption, the mean serum $25 \mathrm{OHD}(54 \mathrm{nmol} / \mathrm{L})$ was above the level $(50 \mathrm{nmol} / \mathrm{L})$ considered by the IOM, at least for skeletal health, as covering the vitamin D requirements of $\geq 97.5 \%$ of the North-American population (14). Figure 1 illustrates the time-dependent changes in serum $25 \mathrm{OHD}$ in relation with the $50 \mathrm{nmol} / \mathrm{L}$ level for sufficient concentration as stated in the IOM guidelines (14). Accordingly, in the FY group, the mean serum 25OHD concentration overcrosses this level between D28 and D56. At that time, as illustrated in Figure 2, the serum PTH level was still above the upper limit of the normal range. However, at
D84, given the additional 4 weeks of FY consumption, serum PTH fell into the normal range, suggesting that correction of secondary hyperparathyroidism was achieved after 3 months of FY consumption (Figure 2). The reduction of the two markers of bone resorption, CTX and TRAP5b, may be interpreted as the functional consequence of the reduced extracellular level of PTH. Besides the $10 \mu \mathrm{g}$ of supplemental vitamin D3, the $86 \%$ higher $\mathrm{Ca}$ intake in the FY group as compared to the $\mathrm{CY}$ group (mean: 1457 vs. $783 \mathrm{mg} / \mathrm{d}$ ) could have substantially contributed to the control of secondary hyperparathyroidism.

As recently reviewed (41), high PTH concentration has been associated with increased risk of cardio-vascular diseases. Among intermediate risk factors, increased blood pressure could be implicated in this association. In our 3 month randomized trial both systolic and diastolic blood presssure remained stable despite a marked fall in serum PTH in the subjects consuming vitamin D an Ca fortified yogurt. Strengths and limitations.

The strengths of this study include a three month randomized controlled trial comparing the effects of $\mathrm{Ca}$ and vitamin $\mathrm{D}$ fortification of a dairy product in women over 60 living in community dwelling accommodation on the relation between the serum level of 25OHD, PTH and two biochemical markers of bone resorption. The study responds to the concept of comparative effectiveness research, since the fortified yogurts were compared to identical but non-fortified dairy products. Another strength is the intention-to-treat analysis supporting the results with the demonstration of the vitamin D status improvement associated with the reduction of both secondary hyperparathyroidism and bone resorption markers in women at moderate risk of fragility fractures. The good compliance to the consumption of the two compared food products during three months can also be considered as an asset in this clinical trial.

A limitation was the uncomplete data related to the dietary survey. Indeed, the 3-day dietary diaries to assess the spontaneous calcium and macronutrient intakes at baseline and during the intervention were not reliably completed by all of the enrolled participants. Therefore, it cannot be ruled out that uneven bone-related food consumption might have influenced the magnitude of the differences in the reported biochemical variables between the two experimental groups. Another limitation is the difficulty to control the vitamin D supply from both cutaneous and food sources. The rise in the serum level of $25 \mathrm{OHD}$ in the control group reflects this difficulty. However, it also underscores the importance of quantifying the actual effect of the tested fortification as compared to an identical non-fortified product in parallel randomized control trials. The reported mean rise in serum $25 \mathrm{OHD}$ of $22 \mathrm{nmol} / \mathrm{L}$, modifying the vitamin $\mathrm{D}$ status from insufficiency $(34 \mathrm{nmol} / \mathrm{L})$ to sufficiency $(56 \mathrm{nmol} / \mathrm{L})$ after 3 months of $10 \mu \mathrm{g} / \mathrm{d}$ of vitamin D3 supplied by the consumption of fortified yogurts was determined in white postmenopausal women living in a community dwelling home. This doseresponse relationship may not apply to other ethnic or racial 


\section{JNHA: GERIATRIC SCIENCE}

population of postmenopausal women living in similar housing communities (30).

Conclusions. The daily consumption of two fortified yogurts for three months providing $520 \mathrm{mg}$ of Ca and $10 \mu \mathrm{g}$ (400 IU) of vitamin D3 daily, compared to a non fortified equivalent dairy product, increased the mean serum level of $250 \mathrm{HD}$ above 50 $\mathrm{nmol} / \mathrm{L}$, almost controlled secondary hyperparathyroidism and reduced serum markers of bone resorption. This comparative effectiveness clinical trial confirms the usefulness of a nutritional approach consisting in enriching dairy products with $\mathrm{Ca}$ and vitamin D3 in order to prevent the acceleration of bone turnover in women at risk of fragility fractures.

Acknowledgments: J.P.B, V.B. and S.A. designed the study; S.A. supervised the practical carrying out of the clinical trial; J.P.B., V.B. and S.W. analyzed the data; J.P.B and V.B. wrote the manuscript; J.P.B. had the primary responsibility for final content. All authors read and approved the final manuscript.

\section{Funding source: Yoplait France, 150 Rue Galliéni, 92641 Boulogne Cedex, France.}

Disclosure summary: J.P.B. is clinical consultant for Yoplait France; V.B. is a scientific collaborator of Yoplait France; S.A. and S.W. have nothing to disclose.

\section{References}

1. Lips P. Vitamin D deficiency and secondary hyperparathyroidism in the elderly: consequences for bone loss and fractures and therapeutic implications. Endocr Rev. 2001;22(4):477-501.

2. Naylor K, Eastell R. Bone turnover markers: use in osteoporosis. NatRevRheumatol 2012;8(7):379-389.

3. Bonjour JP, Benoit V, Payen F, Kraenzlin M. Consumption of yogurts fortified in vitamin $\mathrm{d}$ and calcium reduces serum parathyroid hormone and markers of bone resorption: a double-blind randomized controlled trial in institutionalized elderly women. J Clin Endocrinol Metab. 2013;98(7):2915-2921.

4. Chapuy MC, Arlot ME, Duboeuf F, Brun J, Crouzet B, Arnaud S, Delmas PD, Meunier PJ. Vitamin D3 and calcium to prevent hip fractures in the elderly women. N Engl J Med. 1992;327(23):1637-1642.

5. Dawson-Hughes B, Harris SS, Krall EA, Dallal GE. Effect of calcium and vitamin D supplementation on bone density in men and women 65 years of age or older. N Engl J Med. 1997:337(10):670-676.

6. Boonen S, Lips P, Bouillon R, Bischoff-Ferrari HA, Vanderschueren D, Haentjens $P$. Need for additional calcium to reduce the risk of hip fracture with vitamin $d$ supplementation: evidence from a comparative metaanalysis of randomized controlled trials. J Clin Endocrinol Metab. 2007;92(4):1415-1423

7. Bischoff-Ferrari HA, Dawson-Hughes B, Willett WC, Staehelin HB, Bazemore MG, Zee RY, Wong JB. Effect of Vitamin D on falls: a meta-analysis. Jama. 2004;291(16):1999-2006

8. Greenspan SL, Resnick NM, Parker RA. Early changes in biochemical markers of bone turnover are associated with long-term changes in bone mineral density in elderly women on alendronate, hormone replacement therapy, or combination therapy: a three-year, double-blind, placebo-controlled, randomized clinical trial. J Clin Endocrinol Metab. 2005;90(5):2762-2767.

9. Johnell O, Oden A, De Laet C, Garnero P, Delmas PD, Kanis JA. Biochemical indices of bone turnover and the assessment of fracture probability. Osteoporos Int. 2002;13(7):523-526.

10. Bonjour JP, Kohrt W, Levasseur R, Warren M, Whiting S, Kraenzlin M. Biochemical markers for assessment of calcium economy and bone metabolism: application in clinical trials from pharmaceutical agents to nutritional products. Nutr Res Rev. 2014:27:252-267.

11. Heaney RP. Design Considerations for Clinical Investigations of Osteoporosis. In Marcus M, Feldman D, Nelson DA, Rosen CJ, editors. Osteoporosis. 3rd Edition ed. Amsterdam: Elsevier, Inc; 2008. p. 1598-1620.

12. Kaats GR, Preuss HG, Leckie RB. Comparative Effectiveness Research (CER): Opportunities and Challenges for the Nutritional Industry. J Am Coll Nutr. 2009;28(3):234-237.

13. Michalek JE, Preuss HG, Croft HA, Keith PL, Keith SC, Dapilmoto M, Perricone NV, Leckie RB, Kaats GR. Changes in total body bone mineral density following a common bone health plan with two versions of a unique bone health supplement: a comparative effectiveness research study. Nutr J. 2011;10:32.

14. Ross AC, Manson JE, Abrams SA, Aloia JF, Brannon PM, Clinton SK, DurazoArvizu RA, Gallagher JC, Gallo RL, Jones G, et al. The 2011 report on dietary reference intakes for calcium and vitamin D from the Institute of Medicine: what clinicians need to know. JClinEndocrinolMetab. 2011;96(1):53-58.

15. Holick MF, Binkley NC, Bischoff-Ferrari HA, Gordon CM, Hanley DA, Heaney RP, Murad MH, Weaver CM. Evaluation, treatment, and prevention of vitamin D deficiency: an Endocrine Society clinical practice guideline. J Clin Endocrinol Metab. 2011;96(7):1911-1930.

16. Kanis JA, Oden A, Johansson H, Borgstrom F, Strom O, McCloskey E. FRAX and its applications to clinical practice. Bone. 2009;44(5):734-743.

17. Kanis JA, McCloskey E, Johansson H, Oden A, Leslie WD. FRAX $((\mathrm{R}))$ with and without bone mineral density. Calcif Tissue Int. 2012;90(1):1-13.

18. Thompson FE, Byers T. Dietary assessment resource manual. J Nutr. 1994;124(11 Suppl):2245S-2317S.

19. Bonjour JP, Benoit V, Rousseau B, Souberbielle JC. Consumption of Vitamin D-and Calcium-Fortified Soft White Cheese Lowers the Biochemical Marker of Bone Resorption TRAP 5b in Postmenopausal Women at Moderate Risk of Osteoporosis Fracture. J Nutr. 2012;142(4):698-703.

20. Dawson B, Trapp RG. Basic and Clinical Biostatistics. 3rd ed. New York: Lange Medical Books/McGraw-Hill; 2001.

21. Sanders KM, Stuart AL, Williamson EJ, Simpson JA, Kotowicz MA, Young D, Nicholson GC. Annual high-dose oral vitamin D and falls and fractures in older women: a randomized controlled trial. JAMA. 2010;303(18):1815-1822.

22. Bolland MJ, Grey A, Gamble GD, Reid IR. The effect of vitamin D supplementation on skeletal, vascular, or cancer outcomes: a trial sequential meta-analysis. Lancet Diabetes Endocrinol. 2014;2(4):307-320.

23. Avenell A, Mak JC, O'Connell D. Vitamin D and vitamin D analogues for preventing fractures in post-menopausal women and older men. Cochrane Database Syst Rev. 2014;4:CD000227.

24. Dawson-Hughes B, Harris SS. High-dose vitamin D supplementation: too much of a good thing? JAMA. 2010;303(18):1861-1862.

25. Grant WB. The effect of vitamin D supplementation on skeletal, vascular, or cancer outcomes. Lancet Diabetes Endocrinol. 2014;2(5):364.

26. Ng K, Hollis BW, Giovannucci EL, Fuchs CS. Reply to PM Brannon et al. Am J Clin Nutr. 2014;100(3):984-986.

27. Mak JC. High-dose oral vitamin D supplementation and risk of falls in older women. JAMA. 2010;304(8):854; author reply 856-857.

28. Bischoff-Ferrari HA, Orav EJ, Willett WC, Dawson-Hughes B. The effect of vitamin D supplementation on skeletal, vascular, or cancer outcomes. Lancet Diabetes Endocrinol. 2014;2(5):363-364.

29. Davies JS, Poole CD. Vitamin D and falls. Lancet Diabetes Endocrinol. 2014;2(7):540-541.

30. Ng K, Scott JB, Drake BF, Chan AT, Hollis BW, Chandler PD, Bennett GG, Giovannucci EL, Gonzalez-Suarez E, Meyerhardt JA, et al. Dose response to vitamin D supplementation in African Americans: results of a 4-arm, randomized, placebocontrolled trial. Am J Clin Nutr. 2014;99(3):587-598.

31. Taylor CL, Carriquiry AL, Bailey RL, Sempos CT, Yetley EA. Appropriateness of the probability approach with a nutrient status biomarker to assess population inadequacy: a study using vitamin D. Am J Clin Nutr. 2013;97(1):72-78.

32. Brannon PM, Mayne ST, Murphy SP, Taylor CL. Vitamin D supplementation in African Americans: dose-response. Am J Clin Nutr. 2014;100(3):982-984.

33. Dawson-Hughes B, Mithal A, Bonjour JP, Boonen S, Burckhardt P, Fuleihan GE, Josse RG, Lips P, Morales-Torres J, Yoshimura N. IOF position statement: vitamin D recommendations for older adults. Osteoporos Int. 2010;21(7):1151-1154.

34. Annweiler C, Montero-Odasso M, Llewellyn DJ, Richard-Devantoy S, Duque G, Beauchet O. Meta-analysis of memory and executive dysfunctions in relation to vitamin D. J Alzheimers Dis. 2013;37(1):147-171.

35. Bartali B, Devore E, Grodstein F, Kang JH. Plasma vitamin D levels and cognitive function in aging women: the nurses' health study. J Nutr Health Aging. 2014;18(4):400-406.

36. Latimer CS, Brewer LD, Searcy JL, Chen KC, Popovic J, Kraner SD, Thibault O, Blalock EM, Landfield PW, Porter NM. Vitamin D prevents cognitive decline and enhances hippocampal synaptic function in aging rats. Proc Natl Acad Sci U S A. 2014;111(41):E4359-4366.

37. Marcelli C, Chavoix C, Dargent-Molina P. Beneficial effects of vitamin D on falls and fractures: is cognition rather than bone or muscle behind these benefits? Osteoporos Int. 2014.

38. Rolland Y, de Souto Barreto P, Abellan Van Kan G, Annweiler C, Beauchet O, Bischoff-Ferrari H, Berrut G, Blain H, Bonnefoy M, Cesari M, et al. Vitamin D supplementation in older adults: searching for specific guidelines in nursing homes. $\mathbf{J}$ Nutr Health Aging. 2013;17(4):402-412.

39. Barger-Lux MJ, Heaney RP, Dowell S, Chen TC, Holick MF. Vitamin D and its major metabolites: serum levels after graded oral dosing in healthy men. Osteoporos Int. 1998;8(3):222-230.

40. Lips P, Duong T, Oleksik A, Black D, Cummings S, Cox D, Nickelsen T. A global study of vitamin D status and parathyroid function in postmenopausal women with osteoporosis: baseline data from the multiple outcomes of raloxifene evaluation clinical trial. J Clin Endocrinol Metab. 2001;86(3):1212-1221.

41. van Ballegooijen AJ, Reinders I, Visser M, Brouwer IA. Parathyroid hormone and cardiovascular disease events: A systematic review and meta-analysis of prospective studies. Am Heart J. 2013;165(5):655-664, 664 e651-655. 